\title{
Влияние адгезионных слоев на плазмонное усиление фототока металлическими нанодисками в фотодетекторах ближнего ИК-диапазона на базе квантовых точек $\mathrm{Ge} / \mathrm{Si}$
}

\author{
(C) А.И. Якимов ${ }^{1,2}$, В.В. Кириенко ${ }^{1}$, А.А. Блошкин ${ }^{1,3, \text { ฯ А.В. Двуреченский }}{ }^{1,3}$, Д.Е. Уткин ${ }^{1,3}$ \\ ${ }^{1}$ Институт фризики полупроводников им. А.В. Ржанова Сибирского отделения Российской академии наук, \\ 630090 Новосибирск, Россия \\ ${ }^{2}$ Томский государственный университет, \\ 634050 Томск, Россия \\ ${ }^{3}$ Новосибирский государственный университет, \\ 630090 Новосибирск, Россия \\ ^E-mail: bloshkin@isp.nsc.ru
}

Поступила в Редакцию 2 марта 2021 г.

В окончательной редакции 12 марта 2021 г.

Принята к публикации 12 марта 2021 г.

Разработаны планарные плазмонные фотодетекторы $\mathrm{Ge} / \mathrm{Si}$ с квантовыми точками Ge на подложках кремний-на-изоляторе, сопряженные с регулярными массивами металлических нанодисков на их поверхности. Обнаружено, что введение адгезионных слоев, необходимых для формирования стабильных наноструктур из благородных металлов, ведет к подавлению поверхностного плазмонного резонанса. Выбор алюминиевых нанодисков, не требующих адгезионных слоев, позволяет повысить эффективность фотоприемников в 40 раз на длине волны 1.2 мкм и в 15 раз при $\lambda=1.65$ мкм.

Ключевые слова: локализованные поверхностные плазмоны, квантовые точки $\mathrm{Ge} / \mathrm{Si}$, фотоприемники.

DOI: $10.21883 /$ FTP.2021.07.51025.9643

\section{1. Введение}

Резонансное взаимодействие падающих фотонов и электронов проводимости в металлических наночастицах приводит к возбуждению локализованных поверхностных плазмонов (ЛПП) [1-4]. ЛПП привлекательны своей способностью фокусировать свет на нанометровых масштабах и усиливать электромагнитное поле вокруг наночастиц. Благодаря этому фотодетекторы (ФД), сопряженные с плазмонными структурами, крайне чувствительны к свету от видимого до инфракрасного (ИК) диапазона [5-8]. Для сферической металлической частицы, малой по сравнению с длиной волны возбуждающего света, дипольный плазмонный резонанс наступает при условии $\varepsilon_{r}(\omega) \rightarrow-2 \varepsilon_{d}$ [9], где $\varepsilon_{r}(\omega)-$ реальная часть диэлектрической функции металла на частоте $\omega$, а $\varepsilon_{d}-$ диэлектрическая проницаемость окружающей матрицы. Для типичных полупроводников $\varepsilon_{d} \approx 10-15$. Поэтому в области длин волн света, для которых реальная часть диэлектрической функции металла отрицательна и имеет абсолютную величину, близкую к 20-30, можно ожидать высокую эффективность генерации ЛПП.

Обычно изучение ЛПП резонансов и явлений, связанных с ними, сфокусировано на благородных металлах, таких как золото и серебро [10]. В видимой и ближней ИК областях спектра действительная часть диэлектрической функции таких металлов отрицательна и сравнима с полупроводниковыми по абсолютной величине [11-13]. Главным недостатком плазмонных структур на основе благородных металлов является тот факт, что они тре- буют использования адгезионных слоев между диэлектрической матрицей и металлическими наночастицами (обычно для этих целей используют Сr или Тi) для того, чтобы исключить отслаивание пленки металла в процессе взрывной литографии. Использование таких слоев крайне необходимо для структурной стабильности наночастиц, но может быть губительно для характеристик приборов, модифицированных плазмонными структурами. В литературе имеются данные о подавлении поверхностных плазмонов адгезионными слоями в видимой области спектра. Об этом свидетельствуют результаты моделирования спектра поглощения [14], данные спектроскопии комбинационного рассеяния света [15-17], измерения флуоресценции [18] и данные спектроскопии энергетических потерь электронов в золотых наночастицах [19]. Также было изучено влияние адгезионного слоя титана на спектры рассеяния в резонаторах на основе золотого расщепленного кольца в ближней ИК области [20].

В области телекоммуникационных длин волн $(\lambda \sim 1.55$ мкм $)$ реальные части диэлектрических функций хрома и титана в $\sim 20$ раз меньше, чем у золота, а мнимые - в 5 раз больше [12], что влияет на локальный показатель преломления и увеличивает поглощение в металле. В таких условиях введение адгезионного слоя должно приводить к ослаблению ЛПП резонансов, что может являться фактором, ограничивающим возможность достижения высоких характеристик фотодетекторов с плазмонными структурами. Однако в ближнем ИК диапазоне довольно часто 
пренебрегают негативным влиянием подстилающих слоев на характеристики таких фотодетекторов [21-23]. В настоящей работе исследовано влияние титанового адгезионного слоя на плазмонное усиление фототока в ФД ближнего ИК диапазона на основе $\mathrm{Ge} / \mathrm{Si}$-квантовых точек (КТ), интегрированных с регулярными решетками металлических дисков Au/Ti или Al. Гетероструктуры $\mathrm{Ge} / \mathrm{Si}$ с KT Ge были выбраны в качестве активной среды фотодетектора благодаря их чувствительности к ближнему ИК излучению и совместимости со стандартной кремниевой технологией [24]. Электронная структура $\mathrm{Ge} / \mathrm{Si}$ KT представлена в нашей предыдущей работе [25].

\section{2. Методика эксперимента}

Для того чтобы выяснить влияние Ті адгезионного слоя на фотоотклик плазмонных ФД, были изготовлены три типа структур. В качестве первой структуры выступал ФД, не содержащий металлической наноструктуры на поверхности, и он рассматривался в качестве контрольного. На поверхности второй структуры осаждался слой золота толщиной 50 нм. Для связывания золота с поверхностью кремния использовался адгезионный слой титана толщиной $h_{\mathrm{Ti}} 1$ или 5 нм. Затем с помощью технологий электронной литографии на поверхности гетероструктуры формировался двумерный массив дисков (ДМД) (рис. 1,a). Структуры третьего типа содержали алюминиевый ДМД без подстилающего слоя Ті (рис. $1, b)$. Все решетки нанодисков имели квадратную симметрию с периодом $400 \mathrm{HM}$ и диаметром дисков 225 нм (рис. 1, $c$ и $d$ ).

Образцы были выращены методом молекулярнопучковой эпитаксии на установке Riber SIVA-21. B качестве подложки выступали структуры кремний-на-изоляторе (КНИ) с ориентацией (001). Поверхностный слой кремния составлял 50 нм, толщина слоя захороненного слоя $\mathrm{SiO}_{2}$ была равна 155 нм. Использование структур КНИ существенно уменьшило темновой ток, протекающий через толстую подложку $\mathrm{Si}$, что позволило проводить измерения при комнатной температуре. На поверхность подложки был осажден 250-нм слой нелегированного кремния. Буферный слой состоял из трех слоев $\mathrm{Si} \mathrm{c}$ различной температурой роста. Толщины слоев составляли 100, 100 и $50 \mathrm{Hм}$, а температуры роста слоев были равны 500, 650 и $500^{\circ} \mathrm{C}$ соответственно. Активная область ФД состояла из пяти слоев Ge КT, разделенных кремниевыми барьерами толщиной 10 нм. Для роста барьеров использовался двухстадийный процесс, который включал в себя рост 1 нм кремния при температуре $250^{\circ} \mathrm{C}$, за которым следовало осаждение 9 нм $\mathrm{Si}$ при температуре $400^{\circ} \mathrm{C}$. Такая процедура позволяет уменьшить перемешивание $\mathrm{Si}$ и $\mathrm{Ge}$ и сохранить форму и размеры нанокластеров Ge при дальнейшем высокотемпературном осаждении кремния. Для формирования каждого слоя КТ осаждался слоя Ge номиналь-
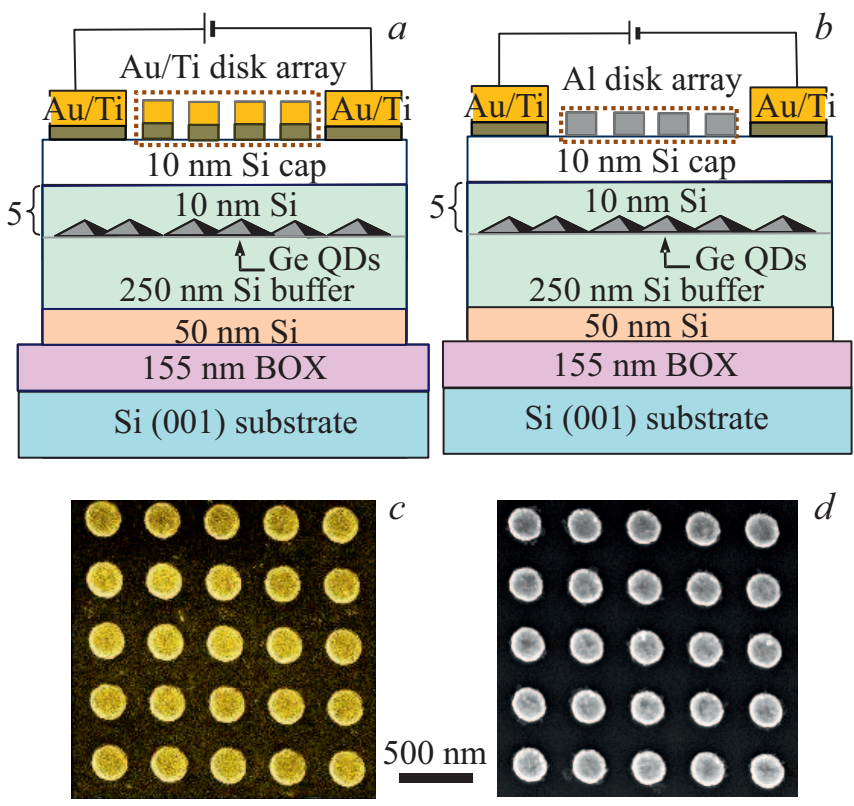

Рис. 1. Схематическое изображение фотодетектора, состоящего из 5 слоев $\mathrm{Ge} / \mathrm{Si}$-квантовых точек, сопряженного с $\mathrm{Au} / \mathrm{Ti}(a)$ и $\mathrm{Al}(b)$ ДМД. Решетки нанодисков имеют квадратную симметрию, период решеток 400 нм, диаметр дисков 225 нм. Толщина $\mathrm{Al}$ и $\mathrm{Au}$ слоя 50 нм. Слой титана 5 нм или 1 нм был осажден между подложкой и пленкой золота для обеспечения адгезии $\mathrm{Au}$ к подложке. Изображение ДМД, полученное методом сканирующей электронной микроскопии, в случае $\mathrm{Au} / \mathrm{Ti}(c)$ и Al $(d)$.

ной толщиной 0.9 нм при температуре $250^{\circ} \mathrm{C}$ со скоростью 0.04 нм/с. Из-за малой поверхностной подвижности адатомов при таких низких температурах формируются островки Ge малого размера с резкой гетерограницей. Из данных сканирующей туннельной микроскопии было установлено, что Ge-островки имеют форму hut-кластеров, ограниченных плоскостями $\{105\}$ с прямоугольным или квадратным основанием [26]. Типичный размер основания КТ составлял $9.4 \pm 3.2 \mathrm{Hм}$, высота $\sim 1 \mathrm{Hм}$, поверхностная плотность нанокластеров $5.2 \cdot 10^{11} \mathrm{~cm}^{-2}$. Исследования методом спектроскопии комбинационного рассеяния света показали, что среднее содержание $\mathrm{Ge}$ в нанокластерах составляет $88 \%$, а средняя деформация в плоскости основания КТ равна -0.036 .

Омические контакты к образцам размером $200 \times 200$ мкм (рис. 1) были изготовлены путем осаждения золота на поверхность образца и дальнейшем отжиге при температуре $350^{\circ} \mathrm{C}$ в течение 5 мин в атмосфере аргона. Слой титана толщиной 5 нм осаждался между пленкой золота толщиной 50 нм и поверхностью ФД для лучшей адгезии. Расстояние между контактами составляло 220 мкм. Образцы были закреплены с помощью теплопроводящего клея на поверхности керамического корпуса. Измерения фототока были выполнены при комнатной температуре при напряжении на образце в 1 В. Засветка образца осуществлялась со стороны подложки. 
По сравнению со случаем освещения ФД со стороны воздуха засветка со стороны подложки дает большее усиление электрического поля в фотодетекторах благодаря более эффективному возбуждению плазмонов в металлических частицах [27]. Кроме того, такой метод засветки позволяет реализовать гибридную схему сборки массивов ФД фокальной плоскости с кремниевой схемой считывания на поверхности устройства [28]. Фотоотклик при нормальном падении света был получен с помощью фурье-спектрометра Vertex-70 компании Bruker co спектральным разрешением в $30 \mathrm{~cm}^{-1}$ в комбинации с низкошумящим токовым предусилителем SR570 компании Stanford Research System. Фототок был нормирован с помощью фотодетектора на основе дейтерированного триглицин-сульфата, легированного L-аланином. Абсолютная величина спектральной чувствительности была получена при облучении структуры серией светодиодов на основе InGaAsP (Roithner Laser Technik) с длинами волн 1.3, 1.45 и 1.55 мкм.

\section{3. Результаты}

Моделирование трехмерного распределения электрического поля в исследуемых структурах осуществлялось в программном пакете Comsol Multiphysics с помощью метода конечных элементов в частотной области [29]. Для возбуждения структуры использовалась плоская электромагнитная волна, поляризованная вдоль направления $y$ и падающая на ФД со стороны подложки. В направлениях $x$ и $y$ использовались периодические граничные условия, а в направлении $z$ были использованы граничные условия типа perfect-matched layer. Частотно-зависимые диэлектрические функции металлов были взяты из работы Rakić и др. [12]. Более детально методика вычислений описана, например, в работе [30]. На рис. 2 представлена интегральная интенсивность электрического поля $\int_{V}|E|^{2} d V$ в зависимости от длины волны падающего света. Интегрирование ведется по объему, в котором располагаются квантовые точки. В диапазоне 1.3-1.6 мкм наблюдается широкий максимум, который включает в себя телекоммуникационные C- и L-зоны. В области более коротких длин волн $(1.03-1.25$ мкм) спектр состоит из серии узких пиков. При увеличении $h_{\text {Ti }}$ уменьшаются амплитуды всех максимумов интенсивности.

Природу оптических резонансов можно установить из анализа пространственного распределения компонент ближнего поля. На рис. 3 представлены цветовые карты распределения вертикальной $\left|E_{z}\right|$ компоненты электрического поля и компоненты $\left|E_{y}\right|$, параллельной плоскости структуры. Изображение построено в сечении $y-z$, проходящем через центр золотого диска, не содержащего подслоя титана. Выбранные длины волн соответствуют максимумам фактора усиления интенсивности электрического поля. Для длины волны $\lambda=1.55$ мкм, соответствующей широкому пику, электрическое поле

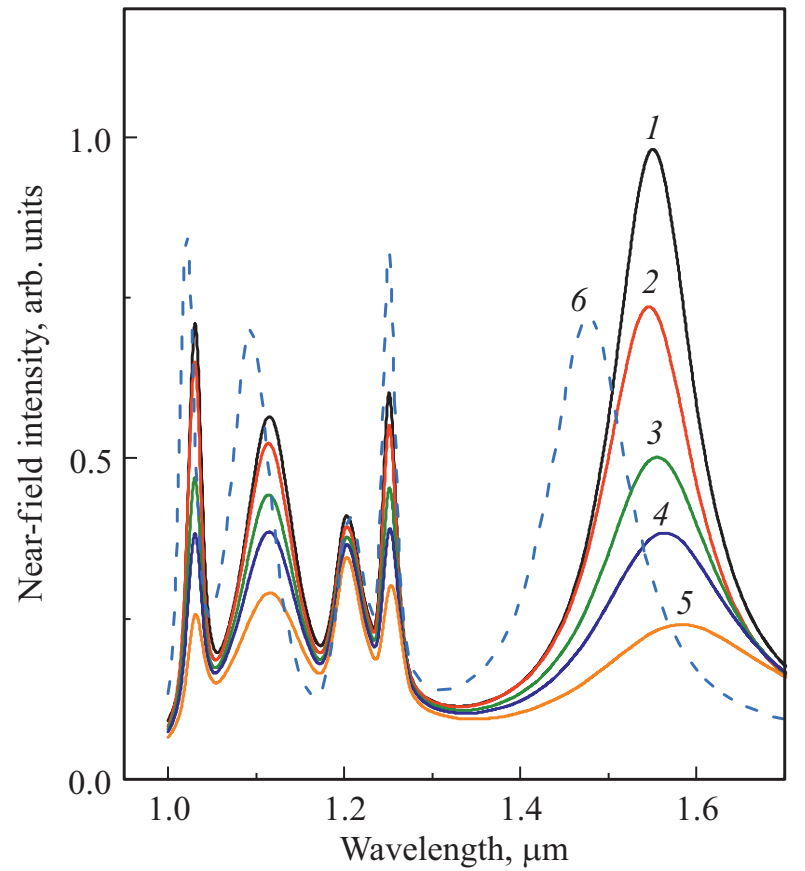

Рис. 2. Рассчитанный спектр интегральной интенсивности электрического поля ДМД на основе $\mathrm{Au} / \mathrm{Ti}$ в зависимости от толщины слоя Ті. Толщина слоя Ті $\left(h_{\mathrm{Ti}}\right)$, нм: $1-0$, $2-1,3-3,4-5,5-10$. Кривая 6 соответствует $\mathrm{Al}$ ДМД на поверхности фотодетектора. Облучение фотодетектора осуществлялось со стороны подложки светом, линейно поляризованным вдоль оси $y$.

значительно усиливается вблизи края золотого диска. Величина электрического поля экспоненциально уменьшается при увеличении расстояния от гетерограницы $\mathrm{Au}-\mathrm{Si}$, что свидетельствует о том, что пик на этой длине волны вызван дипольным ЛПП резонансом. Разница в положении ЛПП резонансов в структурах на основе золота и алюминия, которая достигает 70 нм, вызвана разницей в диэлектрических функциях металлов. Амплитуда ЛПП резонансов в случае алюминиевых наночастиц ослаблена по сравнению со структурами, построенными на базе массива золотых дисков, что объясняется большим поглощением алюминия в этой области длин волн. На рис. 4 показано влияние толщины титанового слоя на эффективность возбуждения ЛПП. Наблюдается ослабление поверхностных плазмонов с увеличением толщины пленки.

По сравнению с ЛПП модами, распределение электрического поля на более коротких длинах волн (1.03-1.25 мкм) сконцентрировано в кремнии между слоем $\mathrm{SiO}_{2}$ и поверхностью. Такие возбуждения известны как волноводные моды $[31,32]$. Верхний слой кремния в КНИ структуре может рассматриваться как планарный волновод благодаря тому, что его показатель преломления существенно превосходит показатели преломления вакуума и захороненного $\mathrm{SiO}_{2}$. Массив металлических дисков на поверхности кремния выступает в качестве 

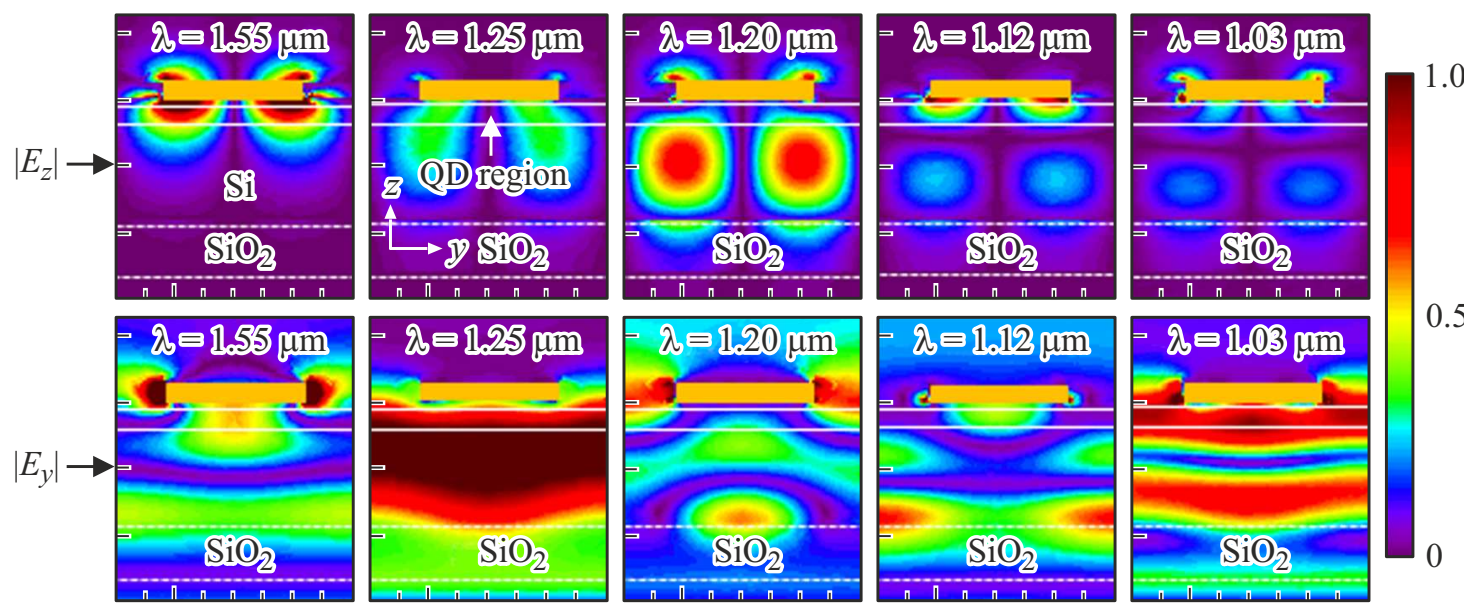

Рис. 3. Пространственное распределение компонент электрического поля $\left|E_{z}\right|-$ верхние графики и $\left|E_{y}\right|-$ нижние графики в плоскости $y-z$ на различных длинах волн, соответствующих максимумам интегральной интенсивности. Плоскость сечения проходит через центр Аu-диска. Желтый прямоугольник показывает положение Аu-диска. Белые сплошные линии ограничивают активную область, содержащую Ge КТ. Штриховые линии обозначает положения захороненного слоя $\mathrm{SiO}_{2}$. Цветовая шкала одинакова для всех графиков и соответствует нормированной амплитуде электрического поля. (Цветной вариант рисунка представлен в электронной версии статьи).
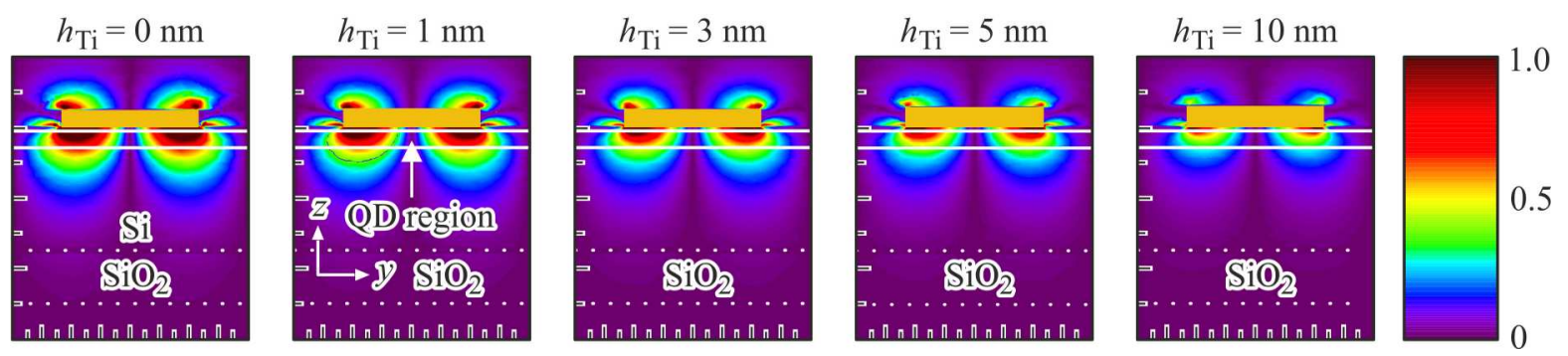

Рис. 4. Пространственное распределение компоненты электрического поля $\left|E_{z}\right|$ в вертикальной плоскости $y$-z для различных толщин адгезионного слоя Ті для фотодетекторов с Аu/Ті ДМД. Данные приведены для ЛПП резонанса на длине волны 1.55 мкм вблизи границы раздела $\mathrm{Au} / \mathrm{Ti}-\mathrm{Si}$. Желтый прямоугольник показывает положение Au-диска. Черные полосы обозначают Тi-слой.

дифракционной решетки, которая позволяет возбудить волноводные моды в слое кремния [33-35]. Планарные волноводные моды различаются поляризацией поля электромагнитного поля. Компонента электрического поля $\left|E_{y}\right|$, параллельная поверхности структуры, доминирует на длинах волн 1.25 и 1.03 мкм. Компонента $\left|E_{y}\right|$ на длине волны 1.25 мкм локализована в центре кремниевого слоя. В то же время на длине волны 1.03 мкм данная компонента имеет узел в этой области пространства (рис. 4). Исходя из этого мы соотнесли пики на 1.25 и 1.03 мкм с модами $\mathrm{TE}_{0}$ и $\mathrm{TE}_{1}$ планарного волновода, распространяющимися вдоль направления $x$ (направление, перпендикулярное плоскости рис. 4). На длине волны 1.2 мкм максимальную величину имеет компонента электрического поля $\left|E_{z}\right|$. Этот пик демонстрирует характеристики волноводной моды $\mathrm{TM}_{0}$, распространяющейся в направлении $y$.

На рис. 5 продемонстрированы спектры фототока в ФД, сопряженных с плазмонными структурами и без них. Фактор усиления фототока показан на рис. $5, b$.
Для получения величины фактора усиления фототока, связанного с наличием ДМД, фототок в плазмонных ФД нормировался на величину фототока в ФД без массива металлических дисков. По сравнению с обычными ФД, структуры с решетками металлических дисков демонстрируют увеличение фототока в диапазоне 1-1.8 мкм. Спектр фактора усиления состоит из двух основных максимумов, локализованных в районе 1.2 и 1.6 мкм. Сравнение с результатами моделирования показывает, что максимум на длине волны 1.6 мкм соответствует плазмонному механизму усиления поля, а коротковолновый максимум (1.2 мкм) связан с гибридизацией плазмонных мод с модами планарного волновода. Так как ширина оптических резонансов в эксперименте достаточно велика, невозможно разделить отдельные волноводные моды в спектре. На длине волны 1.2 мкм ФД с ДМД на основе золота фактор усиления фототока составил 9.8 при $h_{\mathrm{Ti}}=1 \mathrm{Hм}$, и только 1.6 при $h_{\mathrm{Ti}}=5$ нм. Для длинноволнового пика фототока фактор усиления был равен 3.6 и 1.8 при $h_{\text {Ti }}$, равных 1 и 5 нм соответственно. 

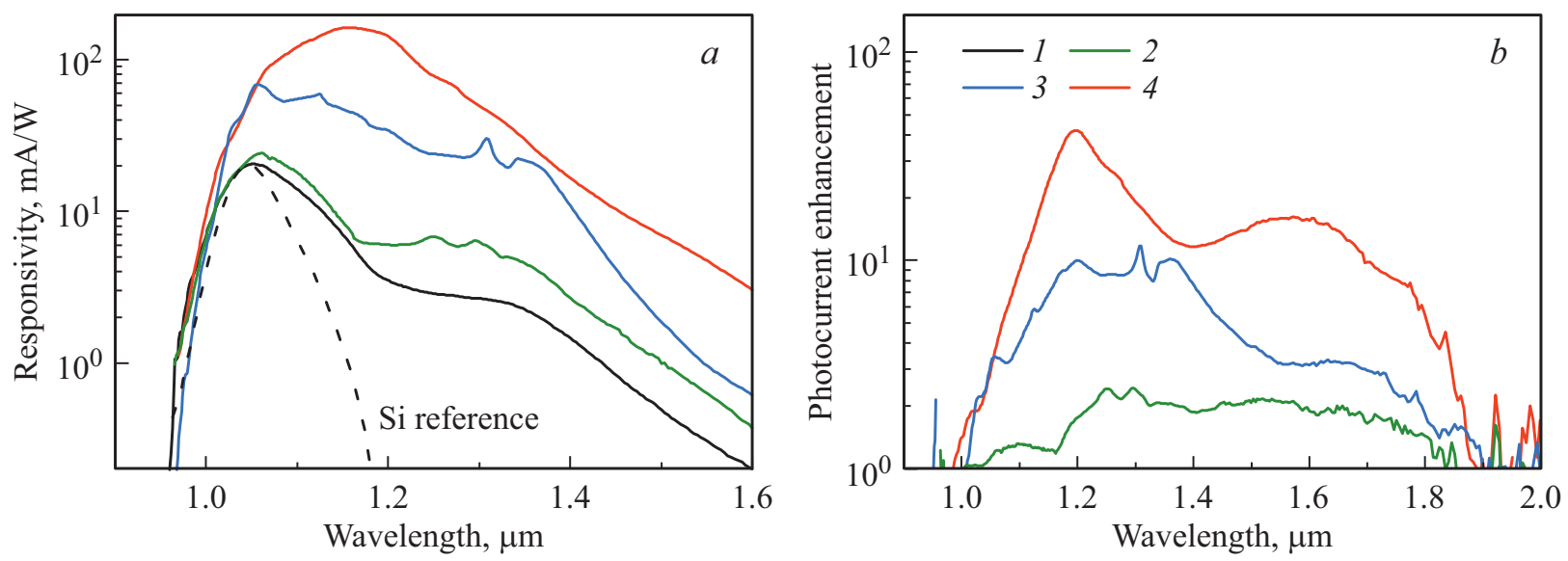

Рис. 5. $а$ - спектральная чувствительность, полученная при комнатной температуре в $\mathrm{Ge} / \mathrm{Si}$ ФД без ДМД (1), с Аu/Ti $\left(h_{\mathrm{Ti}}=1 \mathrm{Hм}\right)(2), \mathrm{Au} / \mathrm{Ti}\left(h_{\mathrm{Ti}}=5 \mathrm{Hм}\right)(3)$ и $\mathrm{Al}$ плазмонными ДМД $(4)$, по сравнению со спектральной чувствительностью ФД на основе чистого кремния. $b-$ спектральная зависимость фактора усиления электрического поля в $Ф Д$ на основе $\mathrm{Al}$ и $\mathrm{Au} / \mathrm{Ti}$ ДМД.

Наибольшее усиление фототока $(40 \times$ на длине волны 1.2 мкм и $15 \times$ на 1.55 мкм) было достигнуто при использовании в структурах с алюминиевыми нанодисками. В целом спектральное положение максимумов усиления фототока хорошо согласуется с результатами моделирования распределения электрического поля, что указывает на то, что рост оптического поглощения в квантовых точках связан с плазмонными наночастицами. В частности, ЛПП резонансы в структурах с алюминиевыми нанодисками смещены в коротковолновую область по сравнению со структурами на основе ДМД Аu/Тi. Однако между экспериментальными и расчетными спектрами имеются различия. Модуляция величины интенсивности ближнего поля в диапазоне от 1 до 1.3 мкм, рассчитанная в рамках моделирования, существенно глубже, чем экспериментально полученная модуляция фототока. Этот эффект может быть объяснен значительным уширением экспериментальных пиков фототока из-за флуктуации размеров и форм металлических дисков. Такой характер типичен для ФД на основе КТ, сопряженных с плазмонными структурами [36,37]. Различие в положении пиков и относительных амплитудах скорее всего связано с ограниченностью применения объемных диэлектрических функций металлов для тонких пленок, что особенно актуально для Тi.

\section{4. Заключение}

В работе исследовано влияние адгезионных слоев Ti на плазмонное усиление фототока металлическими нанодисками в фотодетекторах ближнего ИК диапазона на основе $\mathrm{KT} \mathrm{Ge} / \mathrm{Si}$. Обнаружен рост коэффициента поглощения благодаря возбуждению ЛПП в металлических дисках и волноводных мод в КНИ. Показано, что увеличение толщины подстилающего слоя Ті приводит к уменьшению фактора усиления фототока в плазмонных структурах на основе $\mathrm{Au}$, что обусловлено подавле- нием локализованных поверхностных плазмонов. Для 5-нм слоя титана фактор усиления фототока падает до величины менее двух. Использование алюминиевых нанодисков без адгезионных слоев приводит к существенному улучшению характеристик фотодетектора. Экспериментальные результаты находятся в качественном согласии с результатами моделирования.

\section{Финансирование работы}

Исследование выполнено за счет гранта Российского научного фонда (проект 19-12-00070).

\section{Благодарности}

Авторы благодарят В.А. Армбристера за рост гетероструктур $\mathrm{Ge} / \mathrm{Si}$ методом молекулярно-лучевой эпитаксии. Электронная литография была выполнена в Научноисследовательском центре Физического факультета Новосибирского государственного университета.

\section{Конфликт интересов}

Авторы заявляют, что у них нет конфликта интересов.

\section{Список литературы}

[1] E. Hutter, J.H. Fendler. Adv. Mater., 16, 1685 (2004).

[2] J. Zhang, L. Zhang, W. Xu. J. Phys. D: Appl. Phys., 45, 113001 (2012).

[3] N.C. Lindquist, P. Nagpal, K.M. McPeak, D.J. Norris, S.-H. Oh. Rep. Progr. Phys., 75, 036501(2012).

[4] S. Law, V. Podolskiy, D. Wasserman. Nanophotonics, 2, 103 (2013).

[5] K.R. Catchpole, A. Polman. Opt. Express, 16, 21793 (2008).

[6] H.A. Atwater, A. Polman. Nature Material, 9, 205, (2010).

[7] R. Stanley. Nature Photonics, 6, 409 (2012).

[8] J. Tong, F. Suo, J. Ma, L. Tobing, L. Qian, D. Zhang. OptoElectron. Adv., 2, 180026 (2019) 
[9] S. Link, M.A. El-Sayed. J. Phys. Chem. B, 103, 4212 (1999).

[10] C. Langhammer, B. Kasemo, I. Zorić. J. Chem. Phys., 126, 194702 (2007).

[11] P.B. Johnson, R.W. Christy. Phys. Rev. B, 6, 4370 (1972).

[12] A.D. Rakić, A.B. Djurišić, J.M. Elazar, M.L. Majewski. Appl. Optics, 37, 5271 (1998).

[13] K.M. McPeak, S.V. Jayanti, S.J. Kress, S. Meyer, S. Iotti, A. Rossinelli, D.J. Norris. ACS Photonics, 2, 326 (2015).

[14] Y. Zheng, B. Juluri, X. Mao, T. Walker, T. Huang. J. Appl. Phys., 103, 014308 (2008).

[15] B. Cui, L. Clime, T. Veres. Nanotechnology, 19, 145302 (2008).

[16] M.L. de la Chapelle, H. Shen, N. Guillot, B. Fr emaux, B. Guelorget, T. Toury. Plasmonics, 8, 411 (2013).

[17] T. Siegfried, Y. Ekinci, O.J. Martin, H. Sigg, ACS Nano, 7, 2751 (2013).

[18] H. Aouani, J. Wenger, D. Gérard, H. Rigneault, E. Devaux, T.W. Ebbesen, F. Mahdavi, T. Xu, S. Blair. ACS Nano, 3, 2043 (2009).

[19] S.J. Madsen, M. Esfandyarpour, M.L. Brongersma, R. Sinclair. ACS Photonics, 4, 268 (2017).

[20] B. Lahiri, R. Dylewicz, R.M. De La Rue, N.P. Johnson. Opt. Express, 18, 11202 (2010).

[21] L. Tang, S.E. Kocabas, S. Latif, A.K. Okyay, D.-S. Ly-Gagnon, K.C. Saraswat, D.A.B. Miller. Nature Photonics, 2, 226 (2008).

[22] X. Tang, G.f. Wu, K.W. Lai. J. Mater. Chem. C, 5, 362 (2017).

[23] H. Xiao, S. Lo, Y. Tai, Y. Ho, J. Clark, P. Wei, J. Delaunay. Appl. Phys. Lett., 116, 161103 (2020).

[24] K.W. Wang, D. Cha, J. Liu, C. Chen. Proc. IEEE, 95, 1866 (2007).

[25] A. Yakimov, A. Nikiforov, A. Bloshkin, A. Dvurechenskii. Nanoscale Res. Lett., 6, 208 (2011).

[26] A.I. Yakimov, V.V. Kirienko, V.A. Armbrister, A.A. Bloshkin, A.V. Dvurechenskii. Mater. Res. Express, 3, 105032 (2016).

[27] S.C. Lee, S. Krishna, S.R.J. Brueck. Appl. Phys. Lett., 97, 021112 (2010).

[28] J. Vaillancourt, N. Mojaverian, X. Lu. IEEE Photon. Techn. Lett., 26, 745 (2014).

[29] J. Smajic, C. Hafner, L. Raguin, K. Tavzarashvili, M. Mishrikey. J. Comput. Theor. Nanosci., 6, 763 (2009).

[30] A.I. Yakimov, A.A. Bloshkin, A.V. Dvurechenskii. Photonics Nanostruct., 40, 100790 (2020).

[31] B.N. Kurdi, D.G. Hall. Optics Lett., 13, 175 (1988).

[32] B.J. Soller, H.R. Stuart, D.G. Hall. Optics Lett., 26, 1421 (2001).

[33] H.R. Stuart, D.G. Hall. Appl. Rev. Lett., 69, 2327 (1996).

[34] H.R. Stuart, D.G. Hall. Appl. Phys. Lett., 73, 3815 (1998).

[35] E.T. Yu, D. Derkacs, S.H. Lim, P. Matheu, D.M. Schaadt. Proc. SPIE, 7033, 70331V (2008).

[36] C.-C. Chang, Y.D. Sharma, Y.-S. Kim, J.A. Bur, R.V. Shenoi, S. Krishna, D. Huang, S.-Y. Lin. Nano Lett., 10, 1704 (2010).

[37] R. Kumar, S.A. Ramakrishna. J. Phys. D: Appl. Phys., 51, 165104 (2018)

Редактор А.Н. Смирнов

\section{Influence of adhesion layer on the photocurrent enhancement in near-infrared quantum dot photodetectors coupled with metal nanodisks arrays}

\author{
A.I. Yakimov ${ }^{1,2}$, V.V. Kirienko ${ }^{1}$, A.A. Bloshkin ${ }^{1,3}$, \\ A.V. Dvurechenskii ${ }^{1,3}$, D.E. Utkin ${ }^{1,3}$ \\ ${ }^{1}$ Rzhanov Institute of Semiconductor Physics, \\ Siberian Branch of the Russian Academy of Sciences, \\ 630090 Novosibirsk, Russia \\ 2 Tomsk State University, \\ 634050 Tomsk, Russia \\ ${ }^{3}$ Novosibirsk State University, \\ 630090 Novosibirsk, Russia
}

Abstract We fabricated plasmon-enhanced planar Ge/Si quantum dots photodetectors on Silicon-on-insulator substrate coupled with regular array of metallic nanodisks on photodetector surface. It was demonstrated that insertion of supplementary adhesion layers between silicon substrate and noble metal required for stable structure results in suppression of localized surface plasmons resonance. Selection of the $\mathrm{Al}$ nanodisks without adhesion layers allows to increase the photodetectors efficiency by about 40 times at wavelength $1.2 \mu \mathrm{m}$ and by 15 times at wavelength $1.55 \mu \mathrm{m}$. 